Check for updates

Cite this: RSC Adv., 2019, 9, 30317

Received 28th June 2019

Accepted 26th August 2019

DOI: 10.1039/c9ra04907j

rsc.li/rsc-advances

\section{A zwitterionic polymer as an interfacial layer for efficient and stable perovskite solar cells $\uparrow$}

\author{
Suyuan Zhou, $\dot{t}^{\mathrm{a}}$ Tao Zhu,,$^{\mathrm{a}}$ Luyao Zheng, ${ }^{\mathrm{a}}$ Dong Zhang, ${ }^{\mathrm{c}}$ Wenzhan $\mathrm{Xu},{ }^{\mathrm{a}}$ Lei Liu, ${ }^{\mathrm{a}}$ \\ Gang Cheng, (DD *b Jie Zheng (DD ${ }^{* c}$ and Xiong Gong (DD *a
}

Perovskite solar cells have been rapidly developed in the past ten years. It was demonstrated that the interfacial layer plays an important role in device performance of perovskite solar cells. In this study, we report utilization of a photoinitiation-crosslinked zwitterionic polymer, namely dextran with carboxybetaine modified by methacrylate (Dex-CB-MA), as an interfacial layer to improve the film morphology of the $\mathrm{CH}_{3} \mathrm{NH}_{3} \mathrm{Pbl}_{3}$ photoactive layer and the interfacial contact between the poly $(3,4$ ethylenedioxythiophene)-poly(styrenesulfonate) (PEDOT:PSS) hole extraction layer and $\mathrm{CH}_{3} \mathrm{NH}_{3} \mathrm{Pbl}_{3}$ photoactive layer. It is found that the Dex-CB-MA thin layer forms a better band alignment between the PEDOT:PSS hole extraction layer and $\mathrm{CH}_{3} \mathrm{NH}_{3} \mathrm{Pbl}_{3}$ photoactive layer, and improves the crystallization of the $\mathrm{CH}_{3} \mathrm{NH}_{3} \mathrm{Pbl}_{3}$ photoactive layer, resulting in efficient charge carrier transport. As a result, perovskite solar cells with the PEDOT:PSS/Dex-CB-MA hole extraction layer exhibit more than $30 \%$ enhancement in efficiency and dramatically boosted stability as compared with that with the PEDOT:PSS hole extraction layer. Our studies provide an effective and facile way to fabricate stable perovskite solar cells with high power conversion efficiency.

\section{Introduction}

Perovskite solar cells (PSCs) have attracted great attention in both the academic and industrial sectors as the next-generation photovoltaic technology. ${ }^{1-5}$ Power conversion efficiencies (PCEs) have been rapidly boosted from $3.8 \%$ to over $23.7 \%$ in the past 10 years. ${ }^{6}$ Currently, PSCs incorporating a mesoporous $\mathrm{TiO}_{2}$ electron extraction layer (EEL) and PSCs with a planar heterojunction (PHJ) device structure are under investigation..$^{7-9}$ As compared with the PSCs incorporating the $\mathrm{TiO}_{2}$ EEL, PHJ PSCs are more promising for practical applications due to their advanced potentials for high-throughput manufacturing processibility. ${ }^{10-13}$ However, poor device performance, in particular, low PCEs of PHJ PSCs restricted its practice applications. ${ }^{14}$ To circumvent these issues, the interfacial engineering was applied to improve device performance of $\mathrm{PHJ}$ PSCs. ${ }^{15-17}$ In general, the interfacial layers, which are used to reengineer the interfaces between perovskite photoactive layer and the EEL or the hole extraction layer (HEL), play an

\footnotetext{
${ }^{a}$ Department of Polymer Engineering, The University of Akron, Akron, $\mathrm{OH} 44325$, USA. E-mail: xgong@uakron.edu

${ }^{b}$ Department of Chemical Engineering, University of Illinois at Chicago, Chicago, IL 60607, USA.E-mail: gangcheng@uic.edu

'Department of Chemical and Biomedical Engineering, The University of Akron, Akron, OH 44325, USA.E-mail: zhengj@uakron.edu

$\dagger$ Electronic supplementary information (ESI) available. See DOI: 10.1039/c9ra04907j

$\ddagger$ These authors are contributed to this work equally.
}

important role in device performance of PHJ PSCs. ${ }^{18,19}$ It has been demonstrated that the interfacial layers can tune the energy level at the perovskite/electrode interface, resulting in an ohmic contact from a Schottky barrier ${ }^{20,21}$ and improve charge transport, restricting charge carrier recombination as well. ${ }^{15,17}$ It was also reported that the interfacial layers can enhance the light-trapping, boosting light absorption in the photoactive layer $^{22,23}$ and modulate the film morphology of photoactive layer, reducing surface defects and enhancing the stability of PHJ PSCs..$^{24,25}$ Previously, we demonstrated that 4-lithium styrenesulfonic acid/styrene copolymer, and poly(2,2,6,6-tetramethylpiperidinyloxy-4-yl-methacrylate)-co-(4-benzoylphenyl methacrylate) used as the interfacial layers can boost both PCEs and stability of PHJ PSCs. ${ }^{15,17}$

In this study, we report the utilization a photoinitiationcrosslinked zwitterionic polymer, in particular, dextran with carboxybetaine modified by methacrylate (Dex-CB-MA), as an interfacial layer between the poly(3,4-ethylenedioxythiophene)poly(styrenesulfonate) (PEDOT:PSS) hole extraction layer (HEL) and $\mathrm{CH}_{3} \mathrm{NH}_{3} \mathrm{PbI}_{3}$ photoactive layer. Systematically investigation indicates both the film morphology of $\mathrm{CH}_{3} \mathrm{NH}_{3}$ $\mathrm{PbI}_{3}$ photoactive layer and the interfacial contact between the PEDOT:PSS HEL and $\mathrm{CH}_{3} \mathrm{NH}_{3} \mathrm{PbI}_{3}$ photoactive layer are tuned, resulting in the efficient charge transfer process, restricted surface charge carrier recombination. As a result, the PSCs with the PEDOT:PSS/Dex-CB-MA HEL exhibit a short-circuit current $\left(J_{\mathrm{SC}}\right)$ of $19.90 \mathrm{~mA} \mathrm{~cm}{ }^{-2}$, an open-circuit voltage $\left(V_{\mathrm{OC}}\right)$ of $0.95 \mathrm{~V}$, a fill factor $(\mathrm{FF})$ of $74 \%$ and with a corresponding PCE of 
$13.81 \%$, which is over $30 \%$ enhancement as compared with the PSCs with solely PEDOT:PSS HEL. Moreover, the PSCs with the PEDOT:PSS/Dex-CB-MA HEL exhibit dramatically enhanced stability.

\section{Results and discussion}

Fig. 1a presents the molecular structure of Dex-CB-MA, one of zwitterionic polymers with non-conjugate glucose unites as the backbone and functionalized with zwitterionic carboxyl betaine and double bond methacrylate group. ${ }^{2,27}$ Dex-CB-MA has negligible absorption in visible reign (ESI, Fig. S1 $\dagger$ ), but it can be photo-initiated to crosslink forming a robust thin-film. ${ }^{28-31}$ Fig. 1b shows the transmittance spectra of the ITO/PEDOT:PSS and the ITO/PEDOT:PSS/Dex-CB-MA thin films. Both ITO/ PEDOT:PSS and ITO/PEDOT:PSS/Dex-CB-MA thin films have a similar transmittance spectrum ranging from $350 \mathrm{~nm}$ to $800 \mathrm{~nm}$, indicating that introduction of Dex-CB-MA thin layer on the top of PEDOT:PSS thin film will not tune the transmittance spectrum profile of ITO/PEDOT:PSS anode layer. Over 90\% incident light passing through both ITO/PEDOT:PSS and ITO/PEDOT:PSS/Dex-CB-MA thin films would allow $\mathrm{CH}_{3} \mathrm{NH}_{3}$ $\mathrm{PbI}_{3}$ photoactive layer to absorb large amounts of photons for generating decent photocurrent in PSCs.

It was well-know that the highest occupied molecular orbit (HOMO) presents the energy required to extract an electron from a molecule, which is similar to an oxidation process, and the lowest unoccupied molecular orbit (LUMO) is the energy necessary to inject an electron to a molecule, which is a reduction process. Such processes, therefore, could be measured by cyclic voltammetry (CV) method from the oxidation and reduction potentials. ${ }^{32}$ Fig. $1 \mathrm{c}$ presents the CV curve of Dex-CBMA thin film. The oxidation and reduction potentials are estimated to be $1.8 \mathrm{~V}$, and $-1.5 \mathrm{~V}$, respectively. Thus, the HOMO energy level and the LUMO energy level of Dex-CB-MA thin film are estimated to be $-6.2 \mathrm{eV}$ and $-2.9 \mathrm{eV}$, respectively, according to the empirical equations $E_{(\text {Hомо })}=-e\left[E_{\text {ox (onset) }}+4.4\right]$ and $E_{\text {(LUMO) }}=-e\left[E_{\text {red(onset) }}+4.4\right] .^{32}$

Fig. 2 presents the static contact angles of water on the surfaces of the PEDOT:PSS thin film and the PEDOT:PSS/Dex-
CB-MA thin film, respectively. Compared with the contact angle $\left(12.6^{\circ}\right)$ observed from the PEDOT:PSS thin film, greatly enlarged contact angle $\left(60.6^{\circ}\right)$ observed from of the PEDOT:PSS/ Dex-CB-MA thin film indicates that the Dex-CB-MA thin layer could decrease the surface tension of the PEDOT:PSS thin film, which is favorable for $\mathrm{CH}_{3} \mathrm{NH}_{3} \mathrm{PbI}_{3}$ to form large grain size with less grain boundaries, ${ }^{33}$ resulting in enhanced charge carrier mobility, consequently, boosted $J_{\mathrm{SC}}$ from PSCs. ${ }^{34}$

Scheme 1a displays PSCs device structure of ITO/ PEDOT:PSS/Dex-CB-MA/ $\mathrm{CH}_{3} \mathrm{NH}_{3} \mathrm{PbI}_{3} / \mathrm{PC}_{61} \mathrm{BM} / \mathrm{Al}, \quad$ where $\mathrm{PC}_{61} \mathrm{BM}$ acts as the electron extraction layer and $\mathrm{Al}$ is aluminum, respectively. Scheme $1 \mathrm{~b}$ presents the LUMO and HOMO energy levels of Dex-CB-MA, $\mathrm{CH}_{3} \mathrm{NH}_{3} \mathrm{PbI}_{3}$ and $\mathrm{PC}_{61} \mathrm{BM}$, and the work functions of ITO, PEDOT:PSS and Al, respectively. It is clear that the LUMO energy level of Dex-CB-MA thin film is higher than that of $\mathrm{CH}_{3} \mathrm{NH}_{3} \mathrm{PbI}_{3}$ thin film, indicating that photo-generated electrons from $\mathrm{CH}_{3} \mathrm{NH}_{3} \mathrm{PbI}_{3}$ thin film can be efficiently blocked to contact with the ITO/PEDOT:PSS bilayer anode, suppressing surface charge carrier recombination. As a result, boosted $J_{\mathrm{SC}}$ is expected to be observed from PSCs incorporated with the PEDOT:PSS/Dex-CB-MA HEL. However, the HOMO energy level of Dex-CB-MA thin film is much lower than the work function of PEDOT:PSS and the HOMO energy level of $\mathrm{CH}_{3} \mathrm{NH}_{3} \mathrm{PbI}_{3}$ thin film, so the thickness of the Dex-CBMA layer should be tiny enough otherwise photo-generated holes from $\mathrm{CH}_{3} \mathrm{NH}_{3} \mathrm{PbI}_{3}$ thin film would be blocked and cannot be efficiently collected by the ITO/PEDOT:PSS bilayer anode. Towards the end, Dex-CB-MA with different thicknesses of $1 \mathrm{~nm}, 2 \mathrm{~nm}$, and $5 \mathrm{~nm}$, are investigated (Fig. S2 and Table S1 in $\mathrm{ESI} \dagger)$.

Fig. 3a presents the current density versus voltage $(J-V)$ characteristics of PSCs incorporated with the Dex-CB-MA interfacial layers with different thickness under white light illumination with a light intensity of $100 \mathrm{~mW} \mathrm{~cm}^{-2}$. The device performance parameters are summarized in Table 1 . The PSCs with $\sim 40 \mathrm{~nm}$ PEDOT:PSS HEL exhibit a $J_{\mathrm{SC}}$ of $19.25 \mathrm{~mA} \mathrm{~cm}^{-2}$, a $V_{\mathrm{OC}}$ of $0.80 \mathrm{~V}$, a FF of $68 \%$, and with a corresponding PCE of $10.42 \%$. These device performance parameters are consistent with results reported previously. ${ }^{35,36}$ The PSCs incorporated with the PEDOT:PSS $(\sim 40 \mathrm{~nm}) /$ Dex-CB-MA $(\sim 1 \mathrm{~nm})$ HEL show a $J_{\mathrm{SC}}$ (a)

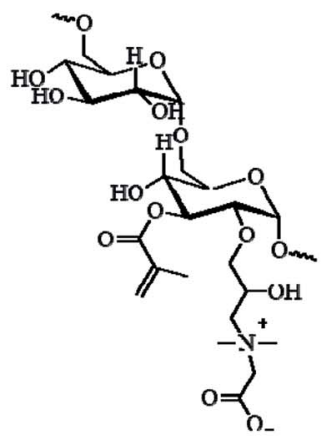

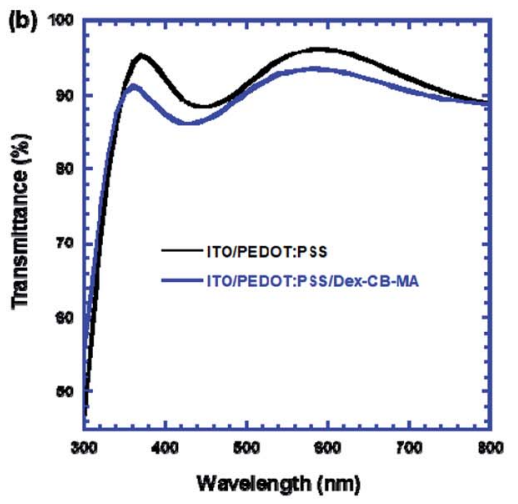

Fig. 1 (a) The molecular structure of Dex-CB-MA, (b) the transmittance spectra of ITO/PEDOT:PSS and ITO/PEDOT:PSS/Dex-CB-MA thin films, (c) the cyclic voltammetry curve of Dex-CB-MA thin film. 
(a)

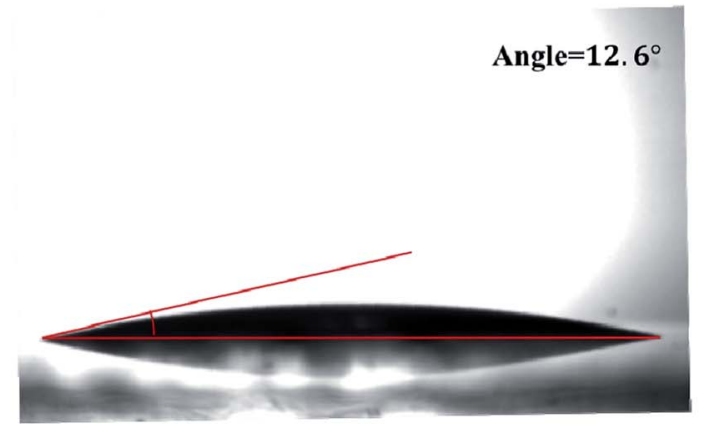

(b)

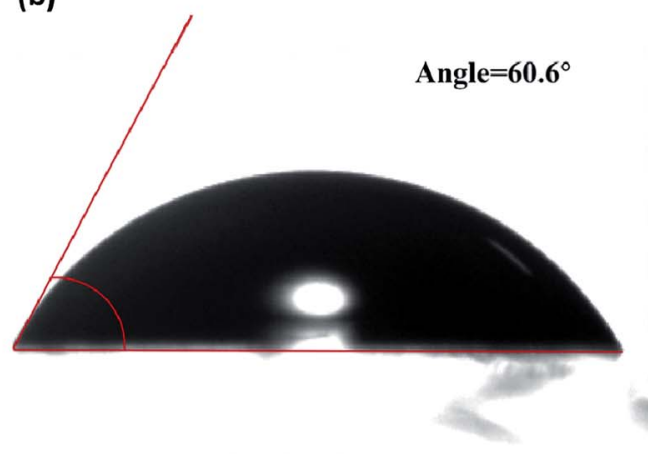

Fig. 2 The contact angles of water on the thin films of (a) glass/PEDOT:PSS thin film and (b) glass/PEDOT:PSS/Dex-CB-MA thin film.

of $18.70 \mathrm{~mA} \mathrm{~cm}{ }^{-2}$, a $V_{\mathrm{OC}}$ of $0.82 \mathrm{~V}$, an $\mathrm{FF}$ of $72 \%$, and with a corresponding PCE of $11.17 \%$. The PSCs incorporated with the PEDOT:PSS $(\sim 40 \mathrm{~nm}) /$ Dex-CB-MA $(\sim 2 \mathrm{~nm})$ HEL exhibit a $J_{\mathrm{SC}}$ of $19.90 \mathrm{~mA} \mathrm{~cm}{ }^{-2}$, a $V_{\mathrm{OC}}$ of $0.95 \mathrm{~V}$, an $\mathrm{FF}$ of $74 \%$, and with a corresponding PCE of $13.81 \%$, which is about over $30 \%$ enhancement as compared with that of the PSCs only incorporated with solely PEDOT:PSS EEL. However, the PSCs incorporated with the PEDOT:PSS $(\sim 40 \mathrm{~nm}) /$ Dex-CB-MA $(\sim 5 \mathrm{~nm})$ HEL show a $J_{\mathrm{SC}}$ of $17.98 \mathrm{~mA} \mathrm{~cm}{ }^{-2}$, a $V_{\mathrm{OC}}$ of $0.85 \mathrm{~V}$, an $\mathrm{FF}$ of $66 \%$, and with a corresponding PCE of $10.11 \%$. Such poor device performance is attributed to the thicker Dex-CB-MA interfacial layer due to its poor electrical conductivity.

Fig. 3b demonstrates the EQE spectra of PSCs based on the PEDOT:PSS HEL and the PEDOT:PSS/Dex-CB-MA (2 nm) HEL. It is observed that two curves have similar profiles while EQE of the PSCs with the PEDOT:PSS/Dex-CB-MA (2 nm) HEL is increased, which is consistent with larger $J_{\mathrm{SC}}$ obtained from the PSCs with PEDOT:PSS/Dex-CB-MA ( $2 \mathrm{~nm}$ ) HEL. The integrated $J_{\text {SC }}$, which is calculated by integration of EQE spectra are 18.27 $\mathrm{mA} \mathrm{cm}{ }^{-2}$ and $19.85 \mathrm{~mA} \mathrm{~cm}^{-2}$ for PSCs with the PEDOT:PSS HEL and the PEDOT:PSS/Dex-CB-MA ( $2 \mathrm{~nm}$ ) HEL, respectively. These values are consistent with those from $J-V$ characteristics.
To study the influence of Dex-CB-MA interfacial layer on the film morphology and crystallinity of $\mathrm{CH}_{3} \mathrm{NH}_{3} \mathrm{PbI}_{3}$ photoactive layer, film morphologies of $\mathrm{CH}_{3} \mathrm{NH}_{3} \mathrm{PbI}_{3}$ coated on the top of the PEDOT:PSS EEL and the PEDOT:PSS/Dex-CB-MA HEL are investigated. The SEM images of $\mathrm{CH}_{3} \mathrm{NH}_{3} \mathrm{PbI}_{3}$ thin layers on the top of the PEDOT:PSS HEL and PEDOT:PSS/Dex-CB-MA HEL, where the thicknesses of Dex-CB-MA are $1 \mathrm{~nm}, 2 \mathrm{~nm}$, and $5 \mathrm{~nm}$ are shown in Fig. 4. The film morphologies of $\mathrm{CH}_{3} \mathrm{NH}_{3} \mathrm{PbI}_{3}$ layers were improved by employing the Dex-CB-MA interfacial layers on the top of PEDOT:PSS layer. It is obvious that pinholes were dramatically reduced from the $\mathrm{CH}_{3} \mathrm{NH}_{3} \mathrm{PbI}_{3}$ thin film on the top of the PEDOT:PSS/Dex-CB-MA (2 nm) layer. Moreover, the largest crystal size with the fewest grain boundaries was also observed from the $\mathrm{CH}_{3} \mathrm{NH}_{3} \mathrm{PbI}_{3}$ thin film on the top of the PEDOT:PSS/Dex-CB-MA (2 $\mathrm{nm}$ ) layer. All these would result in enhanced $J_{\mathrm{SC}}$ and FF for PSCs. Therefore, as expected, the PSCs based on the PEDOT:PSS/Dex-CB-MA (2 nm) HEL possess superior device performance. In contrast, pinholes were easily observed on the surface of $\mathrm{CH}_{3} \mathrm{NH}_{3} \mathrm{PbI}_{3}$ thin film on the top of PEDOT:PSS thin layer. With a rough surface of $\mathrm{CH}_{3} \mathrm{NH}_{3} \mathrm{PbI}_{3}$ thin film on the top of the PEDOT:PSS/Dex-CB-MA (1 nm) HEL, pinholes and defects are still existed, which would result in poor

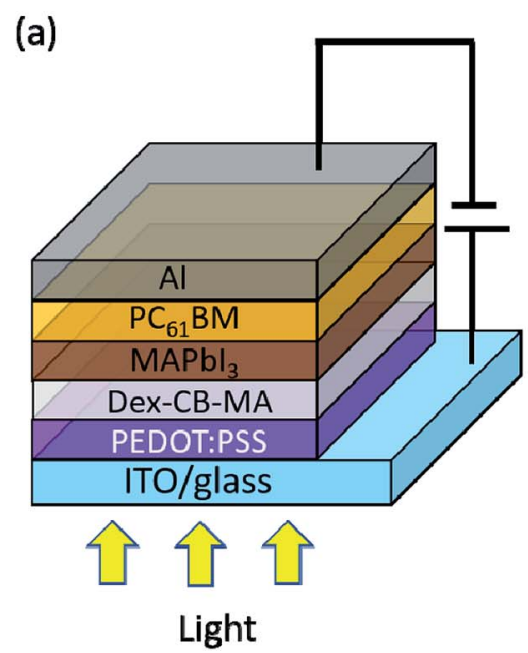

(b)

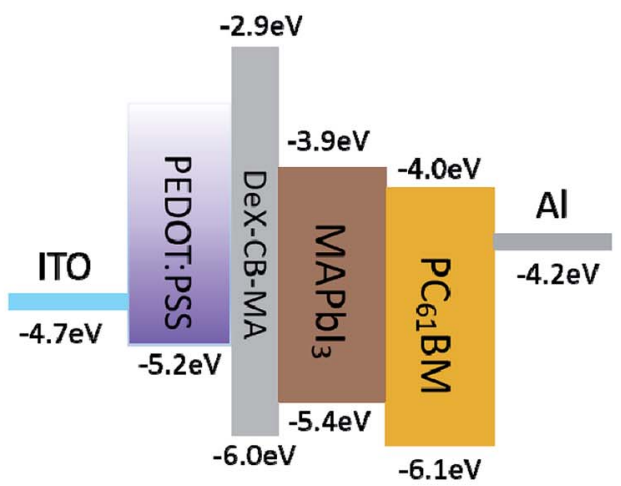

Scheme 1 (a) The device structure of perovskite solar cells, and (b) the $\mathrm{LUMO}$ and $\mathrm{HOMO}$ energy levels of $\mathrm{Dex}-\mathrm{CB}-\mathrm{MA}_{1} \mathrm{CH}_{3} \mathrm{NH}_{3} \mathrm{~Pb} \mathrm{I}_{3}, \mathrm{PC}{ }_{61} \mathrm{BM}$, and the work functions of ITO, PEDOT:PSS and Al. 

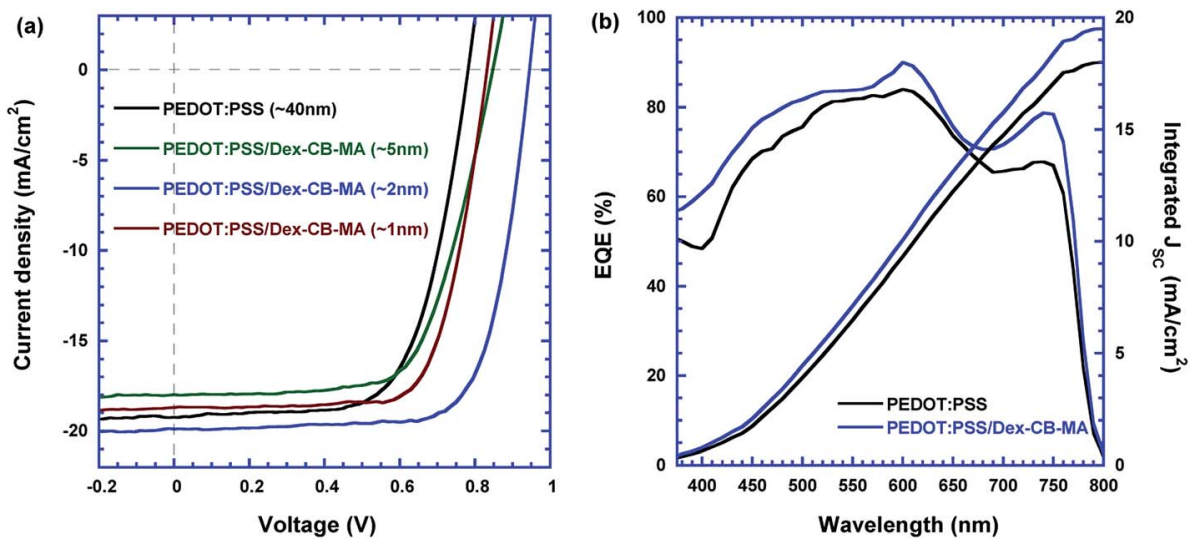

Fig. 3 (a) The J-V characteristics of perovskite solar cells with different hole extraction layers (HEL), and (b) the EQE spectra of perovskite solar cells with the PEDOT:PSS HEL and the PEDOT:PSS/Dex-CB-MA HEL.

Table 1 Device performance parameters of perovskite solar cells ${ }^{a}$

\begin{tabular}{lllll}
\hline Hole extraction layers & $J_{\mathrm{SC}}\left(\mathrm{mA} \mathrm{cm}^{-2}\right)$ & $V_{\mathrm{OC}}(\mathrm{V})$ & Fill factor $(\%)$ & PCE $(\%)$ \\
\hline PEDOT:PSS & $18.11[ \pm 0.3](19.25)$ & $0.78[ \pm 0.3](0.80)$ & $66.2[ \pm 0.2](68.0)$ & $9.35[ \pm 1.03](10.42)$ \\
PEDOT:PSS/Dex $(\sim 5 \mathrm{~nm})$ & $17.13[ \pm 0.7](17.98)$ & $0.83[ \pm 0.3](0.85)$ & $64.1[ \pm 0.2](66.0)$ & $9.11[ \pm 0.96](10.11)$ \\
PEDOT:PSS/Dex $(\sim 2 \mathrm{~nm})$ & $19.21[ \pm 0.3](19.90)$ & $0.92[ \pm 0.2](0.95)$ & $71.3[ \pm 0.3](74.1)$ & $12.61[ \pm 1.09](13.81)$ \\
PEDOT:PSS/Dex $(\sim 1 \mathrm{~nm})$ & $18.26[ \pm 0.6](18.70)$ & $0.82[ \pm 0.1](0.82)$ & $70.9[ \pm 0.8](72.1)$ & $10.61[ \pm 0.42](11.17)$
\end{tabular}

${ }^{a}$ The average parameters were calculated from 18 devices.

$J_{\mathrm{SC}}$. The surface was optimized by the increased thickness of Dex-CB-MA, while the $5 \mathrm{~nm}$ Dex-CB-MA layer decreased the electrical conductivity of PEDOT:PSS/Dex-CB-MA (5 nm) HEL. As a result, $J_{\mathrm{SC}}$ was reduced. Thus, the PSCs based on the PEDOT:PSS/Dex-CB-MA (5 nm) HEL exhibit poor PCE.
To further understand the underlying device performance of PSCs incorporated with the PEDOT:PSS/Dex-CB-MA HEL, surface charge recombination is investigated. Fig. 5a presents the light intensity dependence of $J_{\mathrm{SC}}$ of the PSCs based on the PEDOT:PSS HEL and the PSCs based on the PEDOT:PSS/Dex-CB-MA HEL.
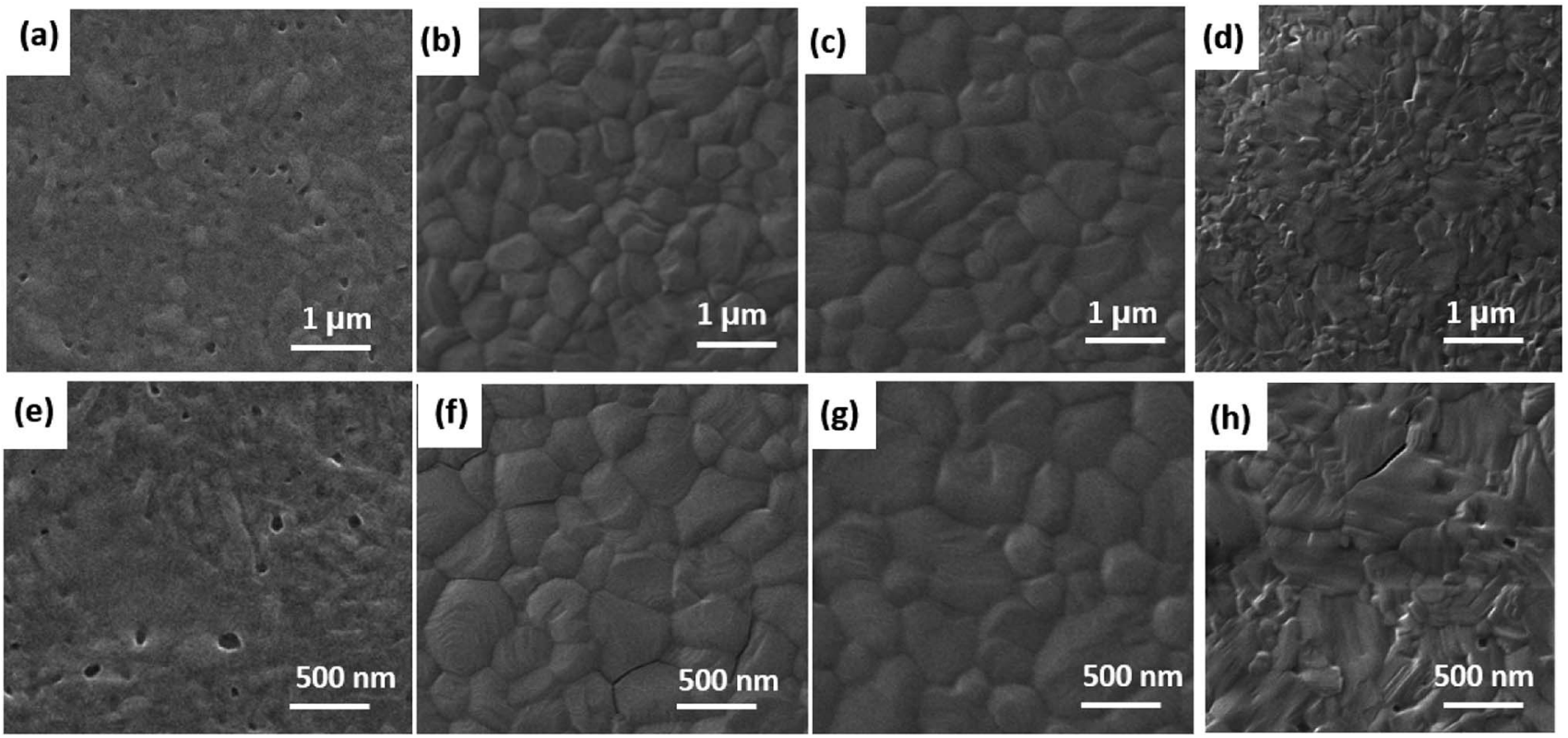

Fig. 4 The top-view SEM images of $\mathrm{CH}_{3} \mathrm{NH}_{3} \mathrm{Pbl}_{3}$ thin films on the top of different thickness of Dex-CB-MA thin layer, (a) and (e) $0 \mathrm{~nm}$, (b) and (f) $1 \mathrm{~nm}$, (c) and (g) $2 \mathrm{~nm}$, (d) and (h) $5 \mathrm{~nm}$. The top images are by 50k times and the bottom images are by 100k times, respectively. 

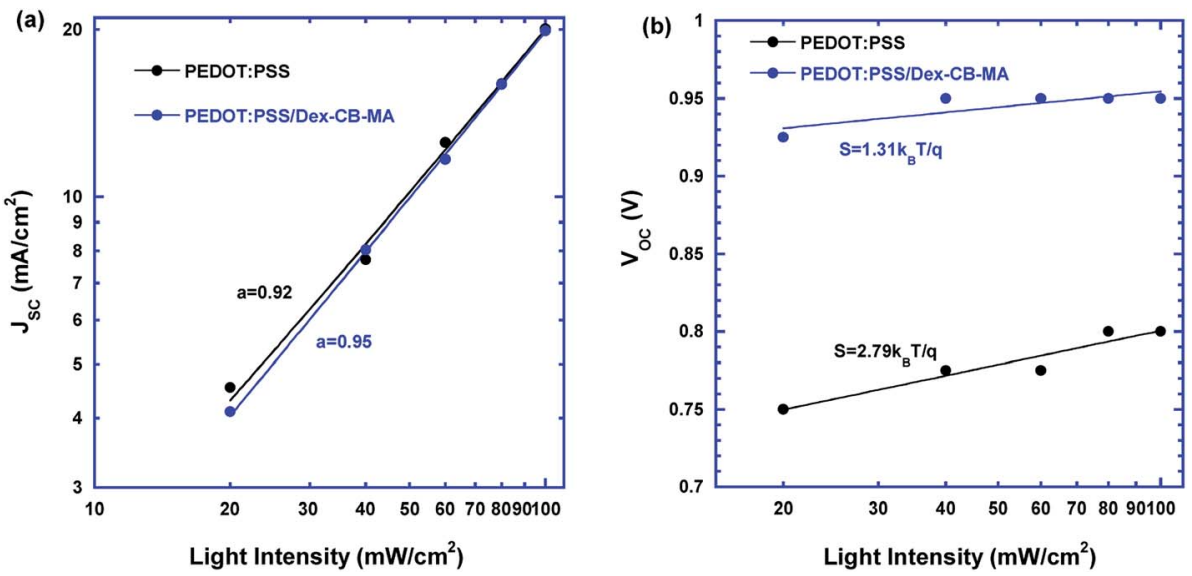

Fig. 5 Light intensity dependence of (a) $J_{S C}$ and (b) $V_{O C}$ of perovskite solar cells with the PEDOT:PSS HEL and the PEDOT:PSS/Dex-CB-MA HEL.

According to the power-law fitting of $J_{\mathrm{SC}} \propto I^{\alpha}$, where $I$ is the intensity of light, and $\alpha$ is the coefficient, ${ }^{36}$ the PSCs based on the PEDOT:PSS HEL have an $\alpha$ of 0.92 , while the PSCs based on the PEDOT:PSS/Dex-CB-MA HEL have an $\alpha$ of 0.95 . The closer to $1 \alpha$ is, the weaker of non-geminated recombination is in PSCs, which indicates that more charge carriers are extracted before they recombine with opposite charges. Fig. 5b shows the light intensity dependence of $V_{\mathrm{OC}}$ of PSCs. With the formula of $V_{\mathrm{OC}} \propto$ $S \ln (I)$, the $V_{\mathrm{OC}}$ of control groups was more dependent on the light intensity. ${ }^{37}$ The $V_{\text {OC }}$ of the PSCs based on the PEDOT:PSS HEL had a slope of $S=2.79 k_{\mathrm{B}} T / q$, where $k_{\mathrm{B}}$ is the Boltzmann constant, $q$ is the elementary charge and $T$ is the room temperature in Kelvin, while the $V_{\mathrm{OC}}$ of the PSCs based on the PEDOT:PSS/Dex-CB-MA HEL had a slope of $S=1.31 k_{\mathrm{B}} T / q$. A smaller $S$ means the less of trap-assisted charge recombination happening in PSCs. ${ }^{11}$ A less possibility of charge carrier recombination process indicates there are less traps acting as the center of recombination in perovskite thin films and more charge carriers are swept out to the electrodes. Those reduced charge carrier recombination process resulting from introducing DexCB-MA layer is also in agreement of enhanced $J_{\mathrm{SC}}$ and $V_{\mathrm{OC}}$.

The $J-V$ characteristics of PSCs in dark were measured to further verify and understand enhanced $V_{\text {OC }}$ for the PSCs based on the PEDOT:PSS/Dex-CB-MA HEL. As demonstrated in Fig. 6, when applied a reverse bias of $-2 \mathrm{~V}$, the dark current density of the PSCs based on the PEDOT:PSS HEL is about 10 times larger than that of the PSCs based on the PEDOT:PSS/Dex-CB-MA HEL. According to the formula of $V_{\mathrm{oc}}=\frac{n k_{B} T}{q} \ln \left(\frac{J_{\mathrm{ph}}}{J_{0}}+1\right),{ }^{38,39}$ where $J_{0}$ is the reverse saturated dark current density, $q$ is the elementary charge, $n$ is diode ideality factor, $T$ is the room temperature in Kelvin and $k_{\mathrm{B}}$ is the Boltzmann's constant, the smaller the value of dark current density is, the higher $V_{\mathrm{OC}}$ can be achieved in devices. The large difference between their dark currents indicates that by introducing the Dex-CB-MA thin layer, the trap states in $\mathrm{CH}_{3} \mathrm{NH}_{3} \mathrm{PbI}_{3}$ layer are suppressed, which is the reason that the PSCs based on the PEDOT:PSS/Dex-CB-MA $(2 \mathrm{~nm}) \mathrm{HEL}$ exhibit higher $J_{\mathrm{SC}}$ and $V_{\mathrm{OC}} \cdot{ }^{17}$
The stabilities of PSCs with different HELs were tested. Fig. 7 presents the self-stabilities of the PSCs with the PEDOT:PSS HELs and the PEDOT:PSS/Dex-CB-MA HEL, where unencapsulated PSCs were stored in the glove box with a nitrogen atmosphere $\left(\mathrm{O}_{2} \sim 100 \mathrm{ppm}, \mathrm{H}_{2} \mathrm{O} \sim 0.1 \mathrm{ppm}\right)$. It is clear that the PSCs with PEDOT:PSS/Dex-CB-MA HEL still maintains over 95\% value of its original PCE after about one week while the PSCs with the PEDOT:PSS HEL remains only $\sim 60 \%$ value of its original PCE. After 20 days, PCE of the PSCs with the PEDOT:PSS/Dex-CB-MA HEL drops to 50\% value of its initial and the PSCs with the PEDOT:PSS HEL left only $\sim 20 \%$ of its initial. For the PSCs based on the PEDOT:PSS HEL, the rapid decay in PCE at the beginning results from the deterioration in the interfacial layer, however, this process happened much later for the PSCs with the PEDOT:PSS/Dex-CB-MA HEL. These

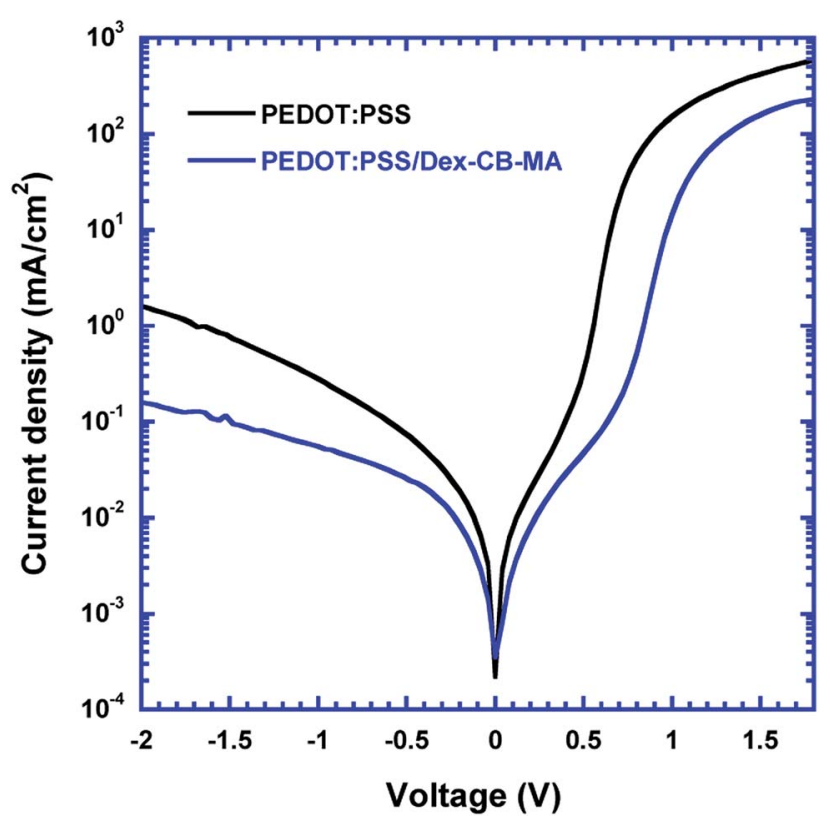

Fig. 6 The J-V characteristics of perovskite solar cells with the PEDOT:PSS HEL and the PEDOT:PSS/Dex-CB-MA HEL, measured in dark. 


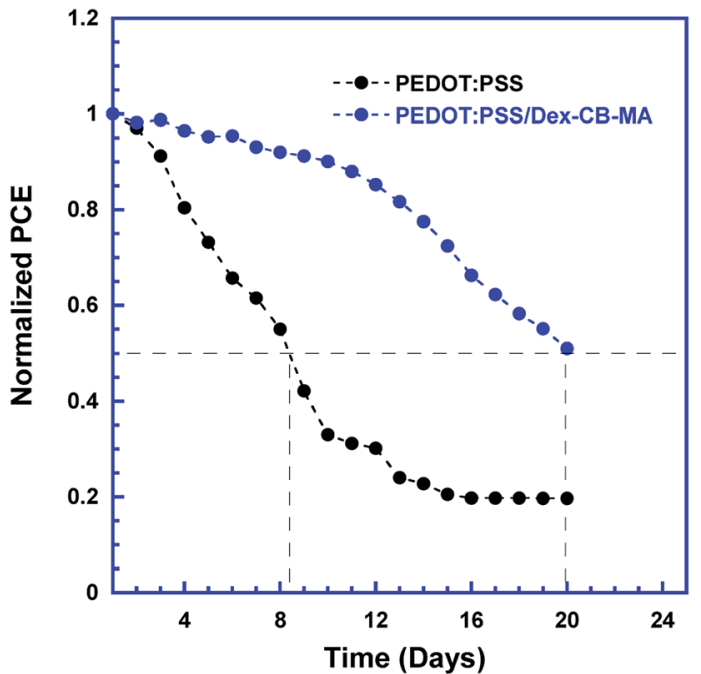

Fig. 7 Self-stability of PSCs with the PEDOT:PSS HEL and the PEDOT:PSS/Dex-CB-MA HEL, respectively.

results indicate that the cross-linkable Dex-CB-MA formed a robust film to prevent the degradation of perovskite material because of the oxygen and moisture. It is obvious that the introduction of Dex-CB-MA interfacial layer can efficiently enhance the stability of PSCs, which is important for the commercial application of PSCs.

\section{Conclusion}

An ultrathin film of photoinitiation-crosslinked zwitterionic polymer, Dex-CB-MA, was used as an interfacial layer to improve both the film morphology of perovskite photoactive layer and the interfacial contact between the PEDOT:PSS hole extraction layer (HEL) and perovskite photoactive layer. It was found that the Dex-CB-MA interfacial layer can induce efficient charge transfer process in perovskite solar cells. As a result, the perovskite solar cells with the PEDOT:PSS/Dex-CB-MA HEL exhibited over $30 \%$ enhancement in power conversion efficiency as compared with the PSCs based the PEDOT:PSS HEL. In addition, the PSCs with the PEDOT:PSS/Dex-CB-MA HEL exhibited drastically enhanced stability. Thus, the utilization of Dex-CB-MA, a kind of transparent cross-linked polymer as an interfacial layer to reengineer the interfacial section in the solution-processed perovskite photoactive layer provides an effective and facile way to fabricate stable perovskite solar cells with high power conversion efficiency and good stability.

\section{Experimental section}

\subsection{Materials}

$N, N$-dimethylglycine ethyl ester (98\%) was purchased from TGI. Lead iodide $\left(\mathrm{PbI}_{2}, 99.9985 \%\right.$ metals basis) was purchased from Alfa Aesar. PEDOT:PSS (SCA 388-20) was purchased from Heraeus. Phenyl- $\mathrm{C}_{61}$-butyric acid methyl ester $\left(\mathrm{PC}_{61} \mathrm{BM}, 99.5 \%\right)$ was purchased from Solenne BV. Toluene (anhydrous, 99.8\%), dimethylformamide (DMF, anhydrous, 99.8\%), ethanol (anhydrous, >99.5\%), dextran (10 kDa), sodium hydroxide (pelleted, >97\%) and chlorobenzene (anhydrous, 99.8\%) were purchased from Sigma-Aldrich. All materials are used as received without further treatment. Methylammonium iodide (MAI, $\mathrm{CH}_{3} \mathrm{NH}_{3} \mathrm{I}$ ) was synthesized through hydroiodic acid and methylamine in our laboratory. ${ }^{40}$ Dex-CB-MA was prepared based on the method developed in our lab. ${ }^{\mathbf{4 1 , 4 2}}$

\subsection{PEDOT:PSS/Dex-CB-MA thin films}

The ITO (indium tin oxides)/glass substrates were pre-cleaned by detergent, acetone, and isopropanol. Before casting any thin film on the top of ITO/glass substrates, the surface of ITO/ glass substrates was treated by UV/Ozone for 20 minutes (min) at ambient atmosphere. After that, $\sim 40 \mathrm{~nm}$ thin layer of PEDOT:PSS was spin-coated on the top of ITO/glass substrates with a spin speed of $3500 \mathrm{rpm}$ for 30 seconds (s), followed with thermal annealing at $150{ }^{\circ} \mathrm{C}$ on the hotplate for $10 \mathrm{~min}$. The Dex-CB-MA thin films with different thicknesses were deposited on the top of PEDOT:PSS cast on the ITO/glass substrates from Dex-CB-MA (0.5 mg mL $\left.\mathrm{mL}^{-1}\right)$ mixed with 1\% 2-hydroxy-4'-(2hydroxyethoxy)-2-methyl propiophenone (as an initiator) with different spin-speed ranged from $1500 \mathrm{rpm}$ to $3500 \mathrm{rpm}$. After that, the Dex-CB-MA thin films were immediately transferred to a glovebox with a nitrogen atmosphere, followed with UV light (365 nm) exposure for 2 hours at room temperature to photocrosslink the Dex-CB-MA thin films.

The transmittance spectra of both PEDOT:PSS thin layer and PEDOT:PSS/Dex-CB-MA thin layer were measured on HP 8453 spectrophotometer in ambient condition. The thicknesses of thin films were measured on a DektakXT surface profile system and further confirmed by atomic force microscopy (AFM) on Park System XE8. The top view images of scanning electron microscopy (SEM) of thin films were obtained on Tescan LYRA3. The top images are by the SEM HV: $30.0 \mathrm{kV}$, SEM MAG: $50.0 \mathrm{k} \times$ and the view field: $4.15 \mu \mathrm{m}$. The bottom images are by the SEM HV: $30.0 \mathrm{kV}$, SEM MAG: $100.0 \mathrm{k} \times$ and the view field: $2.08 \mu \mathrm{m}$. Cyclic voltammetry spectrum of Dex-CB-MA thin film was obtained via the Gamry 600 plus to measure the oxidation and reduction potentials of Dex-CB-MA. Pt wire was used as the counter electrode. The $\mathrm{Ag} / \mathrm{AgCl}$ electrode was used as the reference electrode while $0.1 \mathrm{M}$ lithium perchlorate in acetonitrile used as the electrolyte. The contact angles of water on both PEDOT:PSS and PEDOT:PSS/Dex-CB-MA thin layers were measured on Angle Analysis Equipment from AST Products VCA Optima.

\subsection{Fabrication and characterization of PSCs}

The $\mathrm{CH}_{3} \mathrm{NH}_{3} \mathrm{PbI}_{3}$ photoactive layer was prepared by a two-step deposition method. ${ }^{\mathbf{1 5}}$ Either PEDOT:PSS or PEDOT:PSS/DexCB-MA layers cast on the ITO/glass substrates were preheated at about $85^{\circ} \mathrm{C}$ for $10 \mathrm{~min}$. Warmed $\left(\sim 85^{\circ} \mathrm{C}\right) \mathrm{PbI}_{2} \mathrm{DMF}$ solution (400 $\mathrm{mg} \mathrm{mL}^{-1}$ ) was then spin-coated on the top of either ITO/ PEDOT:PSS or ITO/PEDOT:PSS/Dex-CB-MA layers at a spin rate of $6000 \mathrm{rpm}$ for $20 \mathrm{~s}$, followed with thermal annealing at $85{ }^{\circ} \mathrm{C}$ for $10 \mathrm{~min}$. After $\mathrm{PbI}_{2}$ layer was cooled down to roomtemperature, MAI layer was cast on the top of $\mathrm{PbI}_{2}$ layer from 
MAI ethanol solution ( $40 \mathrm{mg} \mathrm{mL}^{-1}$ ) at a spin rate of $6000 \mathrm{rpm}$ for $35 \mathrm{~s}$. After that, thin films were thermally annealed at $105{ }^{\circ} \mathrm{C}$ for $2 \mathrm{~h}$ on the hotplate for converting $\mathrm{PbI}_{2}$ and MAI into $\mathrm{CH}_{3}$ $\mathrm{NH}_{3} \mathrm{PbI}_{3}$ thin film. After $\mathrm{CH}_{3} \mathrm{NH}_{3} \mathrm{PbI}_{3}$ thin film was cooled down to room temperature, a $\sim 40 \mathrm{~nm} \mathrm{PC}_{61} \mathrm{BM}$ thin layer was spincoated on the top of $\mathrm{CH}_{3} \mathrm{NH}_{3} \mathrm{PbI}_{3}$ thin film at $1500 \mathrm{rpm}$ for $30 \mathrm{~s}$ from $\mathrm{PC}_{61} \mathrm{BM}$ chlorobenzene solution $\left(20 \mathrm{mg} \mathrm{mL}{ }^{-1}\right)$. Afterwards, $\sim 100 \mathrm{~nm}$ aluminum (Al) electrode was thermally deposited on the top of $\mathrm{PC}_{61} \mathrm{BM}$ layer through a shadow mask with a base vacuum of $1 \times 10^{-6} \mathrm{mbar}$. The active area of devices was measured to be $\sim 0.045 \mathrm{~cm}^{2}$.

The current densities versus voltages $(J-V)$ characteristics of PSCs were obtained by using a Keithley model 2400 source measure unit. A Newport Air Mass 1.5 Global (AM1.5 G) fullspectrum solar simulator was applied as the light source. The light intensity was $100 \mathrm{~mW} \mathrm{~cm} \mathrm{~cm}^{-2}$, which is calibrated by utilizing a mono silicon detector (with a KG-5 visible color filter) from the National Renewable Energy Laboratory to reduce the spectral mismatch. The external quantum efficiency (EQE) is obtained by using the solar cell quantum efficiency measurement system (QEX10) from PV measurements with a $300 \mathrm{~W}$ steady-state xenon lamp as the source light.

\section{Conflicts of interest}

There are no conflicts to declare.

\section{Acknowledgements}

The authors acknowledge Air Force Scientific Research Program (FA9550-15-1-0292) and National Science Foundation (EECs 1351785 and EECs 1903303) for financial support.

\section{Notes and references}

1 R. Wang, M. Mujahid, Y. Duan, Z. K. Wang, J. Xue and Y. Yang, Adv. Funct. Mater., 2019, 1808843.

2 J. Yan and B. R. Saunders, RSC Adv., 2014, 4, 43286-43314.

3 W.-J. Yin, J.-H. Yang, J. Kang, Y. Yan and S.-H. Wei, J. Mater. Chem. A, 2015, 3, 8926-8942.

4 J. Xiong, B. Yang, R. Wu, C. Cao, Y. Huang, C. Liu, Z. Hu, H. Huang, Y. Gao and J. Yang, Org. Electron., 2015, 24, 106112.

5 C. Cao, C. Zhang, J. Yang, J. Sun, S. Pang, H. Wu, R. Wu, Y. Gao and C. Liu, Chem. Mater., 2016, 28, 2742-2749.

6 https:/www.nrel.gov/pv/assets/pdfs/pv-efficiencychart.20190103.pdf.

7 Q. Hu, J. Wu, C. Jiang, T. Liu, X. Que, R. Zhu and Q. Gong, ACS Nano, 2014, 8, 10161-10167.

8 Y.-J. Jeon, S. Lee, R. Kang, J.-E. Kim, J.-S. Yeo, S.-H. Lee, S.-S. Kim, J.-M. Yun and D.-Y. Kim, Sci. Rep., 2014, 4, 6953.

9 J. Y. Jeng, Y. F. Chiang, M. H. Lee, S. R. Peng, T. F. Guo, P. Chen and T. C. Wen, Adv. Mater., 2013, 25, 3727-3732.

10 J. Sun, Y. Fu and Q. Wan, J. Phys. D: Appl. Phys., 2018, 51, 314004.

11 C. Wang, C. Zhang, Y. Huang, S. Tong, H. Wu, J. Zhang, Y. Gao and J. Yang, Synth. Met., 2017, 227, 43-51.
12 Q. Chen, H. Zhou, Z. Hong, S. Luo, H.-S. Duan, H.-H. Wang, Y. Liu, G. Li and Y. Yang, J. Am. Chem. Soc., 2013, 136, 622625.

13 Y.-Q. Wang, S.-B. Xu, J.-G. Deng and L.-Z. Gao, R. Soc. Open Sci., 2017, 4, 170980.

14 K. Wang, C. Liu, P. Du, J. Zheng and X. Gong, Energy Environ. Sci., 2015, 8, 1245-1255.

15 L. Zheng, S. Mukherjee, K. Wang, M. E. Hay, B. W. Boudouris and X. Gong, J. Mater. Chem. A, 2017, 5, 23831-23839.

16 G. Yang, C. Wang, H. Lei, X. Zheng, P. Qin, L. Xiong, X. Zhao, Y. Yan and G. Fang, J. Mater. Chem. A, 2017, 5, 1658-1666.

17 K. Wang, C. Liu, C. Yi, L. Chen, J. Zhu, A. Weiss and X. R. Gong, Adv. Funct. Mater., 2015, 25, 6875-6884.

18 C.-C. Chueh, C.-Z. Li and A. K.-Y. Jen, Energy Environ. Sci., 2015, 8, 1160-1189.

19 S. Feng, Y. Yang, M. Li, J. Wang, Z. Cheng, J. Li, G. Ji, G. Yin, F. Song and Z. Wang, ACS Appl. Mater. Interfaces, 2016, 8, 14503-14512.

20 K. M. O'Malley, Z. Li, L. C. Yip, Y. H. Jen and A. K. Adv, Energy Mater., 2012, 2, 82-86.

21 C.-Z. Li, C.-C. Chueh, H.-L. Yip, K. M. O'Malley, W.-C. Chen and K.-Y. A. Jen, J. Mater. Chem., 2012, 22, 8574-8578.

22 J. Y. Kim, S. H. Kim, H. Lee, K. Lee, W. Ma, X. Gong and A. J. Heeger, Adv. Mater., 2006, 18, 572-576.

23 A. K. K. Kyaw, D. H. Wang, D. Wynands, J. Zhang, T.-Q. Nguyen, G. C. Bazan and A. J. Heeger, Nano Lett., 2013, 13, 3796-3801.

24 B. Meng, Y. Fu, Z. Xie, J. Liu and L. Wang, Macromolecules, 2014, 47, 6246-6251.

25 Y. Shi, L. Tan, L. Chen and Y. Chen, J. Mater. Chem. C, 2014, 2, 8054-8064.

26 H. Liu and J. Zhou, Prog. Chem., 2012, 11, 13.

27 Z. Zhang, S. Chen and S. Jiang, Biomacromolecules, 2006, 7, 3311-3315.

28 G. Mahmud, S. Huda, W. Yang, K. Kandere-Grzybowska, D. Pilans, S. Jiang and B. Grzybowski, Langmuir, 2011, 27, 10800-10804.

29 D. M. Guldi, C. Luo, N. A. Kotov, T. Da Ros, S. Bosi and M. Prato, J. Phys. Chem. B, 2003, 107, 7293-7298.

30 A. Sinclair, T. Bai, L. R. Carr, J.-R. Ella-Menye, L. Zhang and S. Jiang, Biomacromolecules, 2013, 14, 1587-1593.

31 L. Chen, X. Ouyang, A. Islam, M. Sain, J. Li, Z.-H. Lu and M. Pervaiz, Adv. Energy Mater., 2019, 1803354.

32 L. Leonat, G. Sbârcea and I. V. Brânzoi, UPB Sci. Bull. Ser. B Chem. Mater. Sci, 2013, 75, 111-118.

33 M. B. Upama, N. K. Elumalai, M. A. Mahmud, D. Wang, F. Haque, V. R. Gonçales, J. J. Gooding, M. Wright, C. Xu and A. Uddin, Org. Electron., 2017, 50, 279-289.

34 C. Bi, Q. Wang, Y. Shao, Y. Yuan, Z. Xiao and J. Huang, Nat. Commun., 2015, 6, 1-7; Q. Wang, Q. Dong, T. Li, A. Gruverman and J. Huang, Adv. Mater., 2016, 28, 67346739.

35 Y. Zheng, C. Wang, J. Yu, F. Yang, J. Zhang, B. Wei and W. Li, J. Phys. D: Appl. Phys., 2017, 50, 475303.

36 N. K. McKinnon, D. C. Reeves and M. H. Akabas, J. Gen. Physiol., 2011, 138, 453-466. 
37 Z. Li, W. Wang, N. C. Greenham and C. R. McNeill, Phys. Chem. Chem. Phys., 2014, 16, 25684-25693.

38 W. Shockley and H. J. Queisser, J. Appl. Phys., 1961, 32, 510519.

39 G. A. H. Wetzelaer, M. Kuik, M. Lenes and P. W. M. Blom, Appl. Phys. Lett., 2011, 99, 153506.

40 X. Huang, K. Wang, C. Yi, T. Meng and X. Gong, Adv. Energy Mater., 2016, 6, 1-8.
41 B. Cao, L. Li, H. Wu, Q. Tang, B. Sun, H. Dong, J. Zhe and G. Cheng, Chem. Commun., 2014, 50, 3234-3237.

42 W. N. E. van Dijk-Wolthuis, O. Franssen, H. Talsma, M. J. Van Steenbergen, J. J. Kettenes-Van Den Bosch and W. E. Hennink, Synthesis, Macromolecules, 1995, 28, 63176322. 